\title{
A randomized trial comparing induction chemotherapy followed by surgery with surgery alone for patients with stage IIIA N2 non-small cell lung cancer (JCOG 9209)
}

\author{
Kanji Nagai, MDa \\ Ryosuke Tsuchiya, MD ${ }^{\mathrm{b}}$ \\ Takashi Mori, MD ${ }^{\mathrm{c}}$ \\ Hiroto Tada, MD \\ Yukito Ichinose, $M D^{\mathrm{e}}$ \\ Teruaki Koike, $M D^{f}$ \\ Harubumi Kato, MDg \\ The Lung Cancer Surgical Study Group \\ of the Japan Clinical Oncology Group
}

\footnotetext{
From the National Cancer Center Hospital East, Chiba, ${ }^{a}$ the National Cancer Center Hospital, Tokyo, ${ }^{\text {b }}$ the National Kinki Chuo Hospital $^{c}$ and the Osaka City General Hospital, ${ }^{\mathrm{d}}$ Osaka, the National Kyushu Cancer Center, Fukuoka, ${ }^{\mathrm{e}}$ the Niigata Cancer Center Hospital, Niigata, ${ }^{\mathrm{f}}$ and Tokyo Medical University, Tokyo, Japan. ${ }^{\mathrm{g}}$

Supported by a Grant-in-Aid for Cancer Research from the Ministry of Health, Labor, and Welfare, Japan.

Received for publication Feb 12, 2002; revisions requested April 30, 2002; revisions received Aug 28, 2002; accepted for publication Sept 12, 2002.

Address for reprints: Kanji Nagai, MD, Department of Thoracic Oncology, National Cancer Hospital East, 6-5-1, Kashiwanoha, Kashiwa, Chiba, 277-8577, Japan (E-mail: knagai@east.ncc.go.jp).

J Thorac Cardiovasc Surg 2003;125:254-60

Copyright () 2003 by The American Association for Thoracic Surgery

0022-5223/2003\$30.00+0

doi: $10.1067 / \mathrm{mtc} .2003 .15$
}

Objective: We performed a prospective randomized trial in patients with potentially resectable stage IIIA N2 non-small cell lung cancer to confirm the efficacy of induction chemotherapy before surgical resection.

Methods: Patients with stage IIIA N2 non-small cell lung cancer, all with histologically or cytologically confirmed metastases to the ipsilateral mediastinal lymph nodes, were randomly assigned to receive either three cycles of induction chemotherapy (cisplatin at $80 \mathrm{mg} / \mathrm{m}^{2}$ on 1 day and vindesine at $3 \mathrm{mg} / \mathrm{m}^{2}$ on 2 days) followed by surgery or surgery alone.

Results: This trial was prematurely terminated because the accrual rate was too slow, which lowered the study's statistical power considerably. From June 1993 through April 1998, a total of 62 patients were enrolled, and 31 patients were assigned to each treatment group. The objective clinical response rate of induction chemotherapy was $28 \%$. Complete resection was achieved in 20 patients in the induction chemotherapy group (65\%) and 24 in the surgery alone group $(77 \%)$. Median follow-up was 6.2 years. Median overall survivals were 17 months for the induction group and 16 months for the surgery alone group. The estimated 1-, 3-, and 5-year survivals, respectively, were $68 \%$ (95\% confidence interval $51 \%-85 \%$ ), $23 \%$ (95\% confidence interval 8\%-38\%), and 10\% (95\% confidence interval $0 \%$ $20 \%$ ) for the induction chemotherapy group and 65\% (95\% confidence interval $48 \%-82 \%$ ), $26 \%$ (95\% confidence interval 11\%-41\%), and $22 \%$ (95\% confidence interval $7 \%-37 \%$ ) for the surgery alone group. There was no statistically significant difference in survival between the groups $(P=.5274)$. Treatment-related death was not observed in either group.

Conclusion: This randomized trial to compare induction chemotherapy (cisplatin and vindesine) followed by surgery with surgery alone for patients with stage IIIA N2 non-small cell lung cancer did not demonstrate a survival difference between the groups, although this may have been because the statistical power was limited.

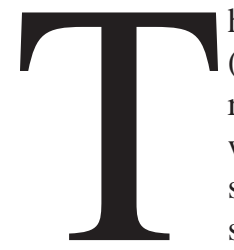

he treatment strategy for patients with non-small cell lung cancer (NSCLC) with ipsilateral mediastinal lymph node involvement (N2) remains controversial. Mountain ${ }^{1}$ concluded that surgical resection was not indicated for these patients, because most of them were suspected to have occult distant metastasis. In Japan, however, surgical resection has been favored for these patients. Japanese researchers reported that a considerable 5-year survival was obtained for cases with 


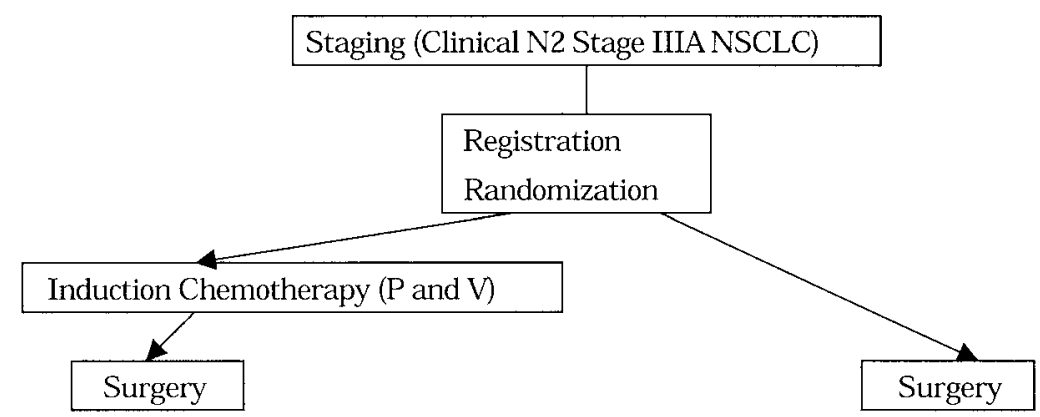

Figure 1. Treatment schema of JCOG 9209. Induction chemotherapy of three cycles of cisplatin $(P)$ at $80 \mathrm{mg} / \mathrm{m}^{2}$ on day 1 and vindesine (V) at $3 \mathrm{mg} / \mathrm{m}^{2}$ on days 1 and 8.

direct node involvement by the primary tumor or with a limited number of N2 nodes. ${ }^{2,3}$ Clinical N2 diagnosis that was based on plain chest radiography was reported to result in a very low resection rate. ${ }^{4}$ Even among the patients with resectable disease, survival was poor compared with the patients whose N2 disease was diagnosed only by mediastinoscopic biopsy or by surgical dissection. ${ }^{3,4}$ Trials of postoperative adjuvant chemotherapy for NSCLC have not shown prognostic benefit. ${ }^{5-8}$ The Japan Clinical Oncology Group (JCOG), performed a phase III trial that compared surgery followed by adjuvant chemotherapy (cisplatin and vindesine) with surgery alone for patients with completely resected stage IIIA NSCLC. ${ }^{7}$ This trial failed to demonstrate therapeutic benefit of the adjuvant chemotherapy. A multivariable analysis, however, demonstrated that pathologically staged N2 disease was a significant prognostic factor for survival. This result indicated that patients with stage IIIA N2 NSCLC should be studied separately from the other patients with IIIA disease.

Although many phase II trials have suggested benefits for induction chemotherapy or induction chemoradiotherapy for patients with stage III N2 NSCLC, ${ }^{9-13}$ the efficacy of these modalities is not definitively established by phase II trials. We planned a prospective randomized trial for patients with potentially resectable stage IIIA N2 NSCLC to compare induction chemotherapy followed by surgery with surgery alone. This study was the first randomized trial for this setting. We used combination chemotherapy with cisplatin and vindesine, which was the most popular combination chemotherapy for NSCLC at that time in Japan. Although this phase III trial was designed to enroll 100 patients in each group within 3 years, starting in June 1993, it was stopped in April 1998 because the patient accrual rate was too slow.

\section{Patients and Methods}

\section{Patient Eligibility}

Histologic or cytologic diagnosis of NSCLC was obtained by bronchoscopic or transcutaneous needle biopsy before registration. All patients had histologically or cytologically documented ipsi- lateral mediastinal lymph node metastasis according to a mediastinoscopic specimen and were previously untreated. Preoperative staging included chest radiography, computed tomography (CT) of the chest, CT or ultrasonography of the upper abdomen, CT or magnetic resonance imaging of the brain with contrast media, and bone scintigraphy. Eligibility criteria included a leukocyte count greater than 4000 cells $/ \mathrm{mm}^{3}$, a platelet count greater than 100,000 cells $/ \mathrm{mm}^{3}$, a hemoglobin count greater than $10 \mathrm{~g} / \mathrm{dL}$, and normal renal and hepatic functions. Other criteria were as follows. (1) Clinical N2 disease was observable on plain chest radiography or CT. (2) Patients had to be younger than 76 years. (3) Complete resection had to be deemed possible. (4) Performance status had to be 0 or 1. (5) Patients had to provide written informed consent. (6) Patients with carcinoid tumor, mucoepidermoid carcinoma, or adenoid cystic carcinoma were excluded. (7) Patients with vena cava syndrome, Pancoast syndrome, T3 tumor with rib involvement, or paratracheal lymph node involvement in a left-sided tumor were excluded.

This phase III protocol was inspected and approved by the JCOG ethical committee. Patient registration was done at the JCOG data center.

\section{Treatment Strategy (Figure 1)}

All eligible patients were randomly assigned to receive either induction chemotherapy followed by surgery or surgery alone. Induction chemotherapy consisted of cisplatin $\left(80 \mathrm{mg} / \mathrm{m}^{2}\right.$ given intravenously on day 1$)$ and vindesine $\left(3 \mathrm{mg} / \mathrm{m}^{2}\right.$ given intravenously on days 1 and 8 ). This treatment cycle was repeated two more times every 4 weeks for patients who had sufficiently recovered from the toxic effects of the previous cycle. Adverse effects of induction chemotherapy were recorded according to the JCOG grade. ${ }^{14}$

Surgical resection was performed within 6 weeks after the last chemotherapy. Surgery was either lobectomy, bilobectomy, or pneumonectomy along with systematic mediastinal lymph node dissection. Patients who were found to have unresectable disease at operation or whose resection was found to be incomplete after operation could receive radiation therapy. Patients whose resection was complete were not allowed to undergo any adjuvant therapy. Treatment for recurrence was not restricted. 
TABLE 1. Patient characteristics

\begin{tabular}{lccc}
\hline & $\begin{array}{c}\text { Induction } \\
\text { chemotherapy }\end{array}$ & Surgery & $\boldsymbol{p}$ value \\
\hline No. of patients & 31 & 31 & \\
Age (y) & $59(32-74)$ & $61(45-74)$ & .3757 \\
Sex (No.) & & & .7884 \\
$\quad$ Men & 20 & 21 & \\
$\quad$ Women & 11 & 10 & \\
Histologic type (No.) & & & .8339 \\
$\quad$ Adenocarcinoma & 21 & 20 & \\
$\quad$ Squamous cell carcinoma & 7 & 8 & \\
$\quad$ Others & 3 & 3 & \\
Clinical T stage (No.) & & & .0327 \\
$\quad$ T1 & 2 & 11 & \\
$\quad$ T2 & 25 & 17 & \\
$\quad$ U3 & 3 & 3 & \\
$\quad$ Unknown & 1 & 0 & \\
\hline
\end{tabular}

TABLE 2. Induction chemotherapy

\begin{tabular}{cccc}
\hline $\begin{array}{l}\text { Performed } \\
\text { cycles }\end{array}$ & Patients & \multicolumn{2}{c}{ Reason for halting } \\
\cline { 3 - 4 } & & $\begin{array}{c}\text { Progressive } \\
\text { disease }\end{array}$ & $\begin{array}{c}\text { Patient } \\
\text { refusal }\end{array}$ \\
\hline 0 & 2 & 1 & 1 \\
1 & 3 & 2 & 1 \\
2 & 4 & 3 & 1 \\
3 & $22(71 \%)$ & &
\end{tabular}

All figures represent numbers of patients.

\section{Statistical Methods}

The number of patients to be enrolled was calculated from the lung cancer survival data at the National Cancer Center in Japan ${ }^{15}$ and Memorial Sloan-Kettering Cancer Center. ${ }^{16}$ Seventy-five patients in each group were required to provide $80 \%$ power to detect a $15 \%$ increase $(25 \%-40 \%)$ in 3-year survival in the induction chemotherapy group compared with the surgery alone group $(\alpha=.05$ $\beta=.2$ ). With an expected $10 \%$ drop-off among the registered patients, a total of 165 patients would be necessary. We therefore aimed at collecting 200 patients in 3 years. All patients randomly assigned in this trial were followed up to date and included in the analysis. Duration of survival or time to recurrence was calculated from the date of random assignment until the date of death, recurrence, or the last follow-up. The probabilities of overall survival and disease-free survival were calculated with the KaplanMeier method. The log-rank test was used to compare survival curves. Statistical differences between proportions were calculated by $\chi^{2}$ test. All calculations were performed with the StatView (version 5.0; SAS Institute Inc, Cary, NC) software package.

\section{Results}

\section{Patient Characteristics}

Because the patient accrual rate was too slow, despite the original aim of 200 patients within 3 years, this study was prematurely terminated in almost 5 years. A total of 62 patients were enrolled at $18 \mathrm{JCOG}$ institutions from June
TABLE 3. Clinical response to induction chemotherapy (n $=29$ )

\begin{tabular}{lrr}
\hline & No. & $\%$ \\
\hline Complete response & 0 & 0 \\
Partial response & 8 & 28 \\
Stable disease & 12 & 41 \\
Progressive disease & 9 & 31
\end{tabular}

TABLE 4. Operations

\begin{tabular}{lcc}
\hline Operation & $\begin{array}{c}\text { Induction } \\
\text { chemotherapy } \\
(\mathbf{n}=\mathbf{3 1})\end{array}$ & $\begin{array}{c}\text { Surgery } \\
(\mathbf{n}=\mathbf{3 1})\end{array}$ \\
\hline R0 & 20 & 24 \\
Pneumonectomy & 2 & 4 \\
Lobectomy & 18 & 20 \\
R1 Pneumonectomy & 1 & 3 \\
Lobectomy & 0 & 1 \\
R2 & 1 & 2 \\
Pneumonectomy & 2 & 2 \\
Lobectomy & 0 & 0 \\
Exploratory thoracotomy & 2 & 2 \\
Not indicated & 5 & 2 \\
\hline
\end{tabular}

All figures represent numbers of patients. A complete resection (R0) was defined as pathologic demonstration of negative tissue margin and an assessment by the surgeon that all detectable disease had been removed. Patients who had a complete gross resection in whom positive margins were found on final pathologic review were classified as having undergone microscopically incomplete resection (R1). Gross residual disease after attempted resection was classified as R2.

1993 through April 1998. Thirty-one patients were randomly allocated to each treatment group. There were no significant differences between the two groups in age, sex, and histologic distribution (Table 1). There were more patients with clinically staged $\mathrm{T} 1$ disease in the surgery alone group than in the induction chemotherapy group.

\section{Induction Chemotherapy}

Twenty-two (71\%) of 31 patients undergoing chemotherapy received three full-dose cycles of induction chemotherapy (Table 2). The objective response rate was $28 \%$ (Table 3 ). Seven of 8 patients with a partial response underwent three full cycles. Another patient with a partial response received two cycles. Severe toxicity (grade 4) was not observed. Grade 3 toxicities were leukocytopenia in $31 \%$, anemia in $14 \%$, and vomiting in $14 \%$. Three (10\%) patients of 31 did not undergo operation because distant metastasis developed in the bone, brain, and contralateral lymph node.

\section{Surgery and Pathologic Examination}

Complete resection was achieved in 20 patients $(65 \%)$ in the induction group and in 24 patients (77\%) in the surgery alone group (Table 4). Exploratory thoracotomy was done 


\section{Probability of Survival}

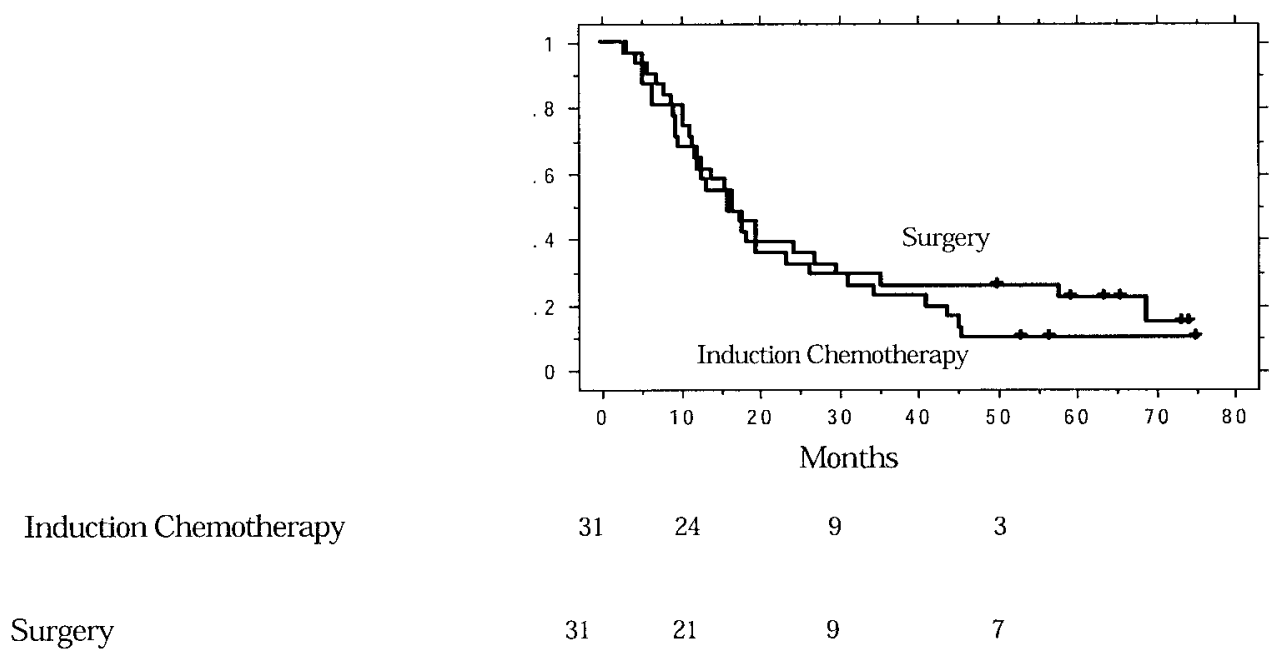

Figure 2. Overall Kaplan-Meier survivals in months after random assignment.

in 5 of the induction group (19\%) and 2 of the surgery alone group $(6 \%)$. Pleural dissemination and intrapulmonary metastases were detected in 3 patients each. The other patient had balky mediastinal node swelling. Complete disappearance of primary tumor in resected specimen occurred in no patients. Four patients had no residual tumor in resected mediastinal lymph nodes according to histologic study, but 1 of them had residual tumor in a hilar lymph node.

\section{Survival Analysis}

Median follow-up was 6.2 years (range 3.4-7.8 years). No patient died within 30 days after the operation. Treatmentrelated death was not observed in either group. Median overall survivals were 17 months for the induction chemotherapy group and 16 months for the surgery alone group. The estimated 1-, 3-, and 5-year survivals, respectively, were $68 \%$ (95\% confidence interval [CI] 51\%-85\%), $23 \%$ (95\% CI 8\%-38\%), and 10\% (95\% CI 0\%-20\%) for the induction group and $65 \%$ (95\% CI 48\%-82\%), 26\% (95\% CI $11 \%-41 \%$ ), and $22 \%$ (95\% CI $7 \%-37 \%$ ) for the surgery alone group (Figure 2). There was no statistically significant difference in survival between the groups $(P=.5274)$. When only patients with completely resected disease were compared, the median survival and estimated 1-, 3- and 5-year survivals, respectively, were 18 months, 80\% $(95 \%$ CI 63\%-97\%), 25\% (95\% CI 6\%-44\%), and 10\% (95\% CI 0\%-23\%) for the induction group and 18 months, $63 \%(95 \%$ CI $44 \%-82 \%), 33 \%$ (95\% CI 14\%-52\%), and $29 \%$ (95\% CI $12 \%-47 \%)$ for the surgery alone group $(P=.6066)$. According to induction chemotherapy response, the median survival and estimated 3-year survival, respectively, were 30 months and 38\% (95\% CI 4\%-72\%) in patients with a partial response, 18 months and 18\% (95\% CI 0\%-41\%) in patients with stable disease, and 12 months and 10\% $(95 \%$ CI 0\%-29\%) in patients with progressive disease. Statistically significant difference in survival was not observed (partial response vs stable disease $P=.5044$, partial response vs progressive disease $P=.0512$, stable disease versus progressive disease $P=.2304$ ). When estimated 1 -, 3 -, and 5-year disease-free survivals, respectively, were compared (Figure 3), they were 57\% (95\% CI 37\%-77\%), $10 \%(95 \%$ CI $0 \%-23 \%)$, and $10 \%$ (95\% CI $0 \%-23 \%)$ for the induction group and 38\% (95\% CI 20\%-56\%), 27\% (95\% CI $11 \%-43 \%)$, and $21 \%$ (95\% CI 5\%-37\%) for the surgery alone group $(P=.5964)$.

\section{Discussion}

Long-term survival after surgical resection of patients with locally advanced NSCLC is poor, especially for those with N2 disease. 3,4,17,18 The JCOG conducted a phase III trial to compare surgery followed by adjuvant chemotherapy with surgery alone for completely resected stage IIIA NSCLC. This trial failed to demonstrate any therapeutic benefit of adjuvant chemotherapy. ${ }^{7}$ The PORT Meta-analysis Trialists ${ }^{19}$ reported that the efficacy of postoperative radiation therapy was not supported. To date postoperative adjuvant therapy has not been proved effective.

Three randomized trials that compared induction chemotherapy followed by surgery with surgery alone or surgery followed by radiation (by Pass and colleagues, ${ }^{20}$ Rosell and associates $^{21,22}$ and Roth and coworkers ${ }^{23,24}$ ) showed significant or marginal survival benefit of induction chemotherapy patients with stage IIIA NSCLC (Table 5). These re- 
Probability of Survival

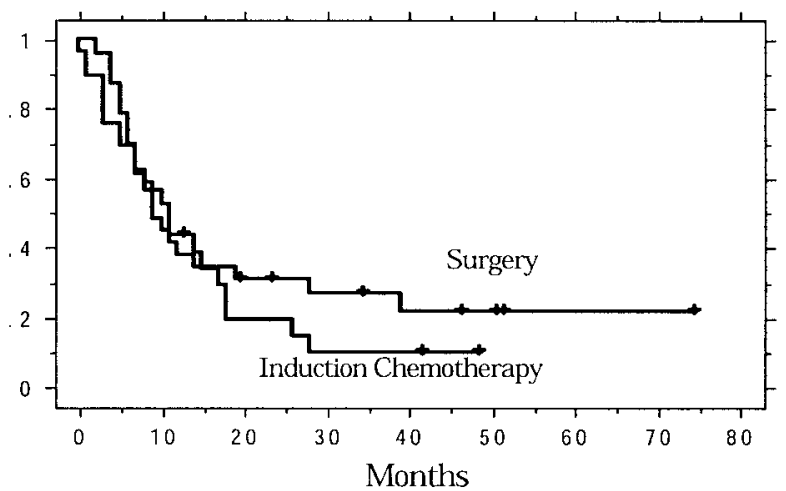

$\begin{array}{lcccc}\text { Induction Chemotherapy } & 31 & 12 & 2 & 0 \\ \text { Surgery } & 31 & 13 & 6 & 2\end{array}$

Figure 3. Disease-free Kaplan-Meier survivals in months after random assignment.

TABLE 5. Reported phase III trials, with or without induction therapy, in other studies of patients with stage IIIA NSCLC and our own

\begin{tabular}{|c|c|c|c|c|c|}
\hline Reference & Stage & Therapy & Patients & MST (m) & $P$ value \\
\hline \multirow[t]{2}{*}{ Pass and colleagues ${ }^{20}$} & IIIA (N2) & $\begin{array}{l}\text { Preoperative and postoperative } \\
\text { etoposide and cisplatin }\end{array}$ & 13 & 29 & .095 \\
\hline & & Postoperative radiotherapy & 14 & 16 & \\
\hline \multirow[t]{2}{*}{ Rosell and associates 21,22} & IIIA & $\begin{array}{l}\text { Preoperative and postoperative } \\
\text { cisplatin, ifosfamide, and } \\
\text { mitomycin }\end{array}$ & 30 & 22 & .005 \\
\hline & & Postoperative radiotherapy & 30 & 10 & \\
\hline \multirow[t]{2}{*}{ Roth and coworkers ${ }^{23,24}$} & IIIA & $\begin{array}{l}\text { Preoperative and postoperative } \\
\text { cyclophosphamide, etoposide, } \\
\text { and cisplatin }\end{array}$ & 28 & 21 & .056 \\
\hline & & Surgery alone & 32 & 14 & \\
\hline \multirow[t]{2}{*}{ Current data } & IIIA (N2) & $\begin{array}{l}\text { Preoperative vindesine and } \\
\text { cisplatin }\end{array}$ & 31 & 17 & .527 \\
\hline & & Surgery alone & 31 & 16 & \\
\hline
\end{tabular}

ports revealed high clinical response rates (35\%-62\%) among patients receiving induction chemotherapy. However, these three trials used different treatment strategies, and Rosell and associates' and Roth and coworkers' study populations included patients with $\mathrm{N} 0$ and N1 disease. ${ }^{21-24}$ We planned to study induction therapy efficacy in the more homogeneous cohort of patients with potentially resectable stage IIIA N2 NSCLC and performed a prospective randomized trial to compare induction chemotherapy followed by surgery with surgery alone.

Although this trial was designed to enroll 100 patients in each group within 3 years, the recruitment was too slow and the trial was discontinued, resulting in a total of only 62 patients in almost 5 yeas. Sixty-two patients (31 patients in each group) is calculated to provide $24 \%$ power to detect a $15 \%$ increase in 3-year survival in the induction chemotherapy group ( $\alpha=.05, \beta=.76$ ). The possibility of a type II error is so high that it may invalidate our data. The greatest contributor to the slow rate was failure to obtain informed consent. The reasons for consent refusal were the lack of rewarding compensation to the patients, prolonged hospitalization in the induction chemotherapy group, and wide reports in the domestic media of the ineffectiveness of chemotherapy for NSCLC. Under the circumstances this trial was prematurely terminated in April 1998.

Unlike previous induction chemotherapy studies, our 
trial population showed poor response to induction chemotherapy (complete resection rate $0 \%$, partial response rate $28 \%$ ), and no survival difference was observed between induction and surgery alone groups. We think that this was because all our eligible patients had N2 disease, unlike previous studies that included patients with N0 or N1 disease.

Chemotherapy regimens with new agents, including paclitaxel, docetaxel, vinorelbine, and gemcitabine, have recently been reported to be effective for advanced NSCLC with fewer, less severe effects. ${ }^{25-29}$ Sandler and associates ${ }^{26}$ reported that as the first-line treatment for NSCLC the regimen of gemcitabine plus cisplatin was superior to cisplatin alone in terms of response rate, time to disease progression, and overall survival. Comella and associates ${ }^{27}$ reported that a cisplatin, gemcitabine, and vinorelbine regimen was associated with a substantial survival gain when compared with a cisplatin and vinorelbine combination for advanced NSCLC. Although a survival benefit conferred by induction chemotherapy before surgical resection for stage IIIA N2 NSCLC was not demonstrated in our trial, these new agent combinations may prove beneficial for locally advanced NSCLC in future trials.

We express our thanks to Junji Yoshida, MD, for his help in this study. We thank Masanori Shimoyama, MD, Chairperson of the JCOG, Nagahiro Saijo, MD, chairperson of Lung Cancer Study Group of the JCOG, and Haruhiko Fukuda, MD, director of the JCOG Data Center for their support in this study. We thank Professor J. Patrick Barron, International Medical Communications Center, Tokyo Medical University, for reviewing the English-language manuscript.

\section{References}

1. Mountain CF. The biological operability of stage III non-small cell lung cancer. Ann Thorac Surg. 1985;40:60-4.

2. Tsuchiya R, Asamura H, Kondo H, Goya T, Naruke T. Extended resection of the left atrium, great vessels, or both for lung cancer. Ann Thorac Surg. 1994;57:960-5.

3. Suzuki K, Nagai K, Yoshida J, Nishimura M, Takahashi K, Nishiwaki $\mathrm{Y}$. The prognosis of surgically resected N2 non-small cell lung cancer: the importance of clinical N status. J Thorac Cardiovasc Surg. 1999;118:145-53.

4. Pearson FG, DeLarue NC, Ilves R, Todd TR, Cooper JD. Significance of positive superior mediastinal nodes identified at mediastinoscopy in patients with respectable cancer of the lung. $J$ Thorac Cardiovasc Surg. 1982;83:1-11.

5. Shields TW, Higgins GA, Humphrey EW, Matthews MJ, Keehn RJ. Prolonged intermittent adjuvant chemotherapy with CCNU and hydroxyurea after resection of carcinoma of the lung. Cancer. 1982;50: 1713-21.

6. Holmes EC, Gail M. Surgical adjuvant therapy for stage II and stage III adenocarcinoma and large-cell undifferentiated carcinoma. J Clin Oncol. 1986;4:710-5.

7. Ohta M, Tsuchiya R, Shimoyama M, Sawamura M, Mori T, Miyazawa N, et al. Adjuvant chemotherapy for completely resected stage III non-small-cell lung cancer. J Thorac Cardiovasc Surg. 1993;106:703-8.

8. Keller SM, Adak S, Wagner H, Herskovic A, Komaki R, Brooks BJ, et al. A randomized trial of postoperative adjuvant therapy in patients with completely resected stage II or IIIA non-small-cell lung cancer. N Engl J Med. 2000;343:1217-22.

9. Albain KS, Rusch, Crowley JJ, Rice TW, Turrisi AT, Weick JK, et al. Concurrent cisplatin/etoposide plus chest radiotherapy followed by surgery for stage IIIA(N2) and IIIB non-small-cell lung cancer: mature results of Southwest Oncology Group phase II study 8805. J Clin Oncol. 1995;13:1880-92.

10. Elias AD, Skarin AT, Leong T, Strauss MG, Lynch T, Jacobs SC, et al. Neoadjuvant therapy for surgically staged IIIA N2 non-small cell lung cancer (NSCLC). Lung Cancer. 1997;17:147-61.

11. Burkes RL, Ginsberg RJ, Shepherd FA, Blackstein ME, Goldberg ME, Waters PF, et al. Induction chemotherapy with mitomycin vindesine and cisplatin for stage III unresectable non-small-cell lung cancer: results of the Toronto phase II trial. J Clin Oncol. 1992;10:580-6.

12. Martini N, Kris MG, Flehinger BJ, Gralla RJ, Bains MS, Burt ME, et al. Preoperative chemotherapy for stage IIIa (N2) lung cancer: the Sloan-Kettering experience with 136 patients. Ann Thorac Surg. 1993; 55:1365-74.

13. Sugarbaker DJ, Herndon JJ, Kohman LJ, Krasna MJ, Green MR. Results of cancer and leukemia group B protocol 8935: a multiinstitutional phase II trimodality trial for stage IIIA (N2) non-small-cell lung cancer. Cancer and Leukemia Group B Thoracic Surgery Group. J Thorac Cardiovasc Surg. 1995;109:473-85.

14. Tobinai K, Kohono A, Shimada Y, Watanabe T, Tamura T, Takeyama $\mathrm{K}$, et al. Toxicity grading criteria of the Japan clinical oncology group. Jpn J Clin Oncol. 1993;23:250-7.

15. Naruke T, Goya T, Tsuchiya R, Suemasu K. Prognosis and survival in resected lung carcinoma based on the new international staging system. J Thorac Cardiovasc Surg. 1988;96:440-7.

16. Martini N, Kris MG, Gralla RJ, Bains MS, McCormack PM, Kaiser LR, et al. The effect of preoperative chemotherapy on the respectability of non-small cell lung carcinoma with mediastinal lymph node metastases (N2 M0). Ann Thorac Surg. 1988;45:370-9.

17. Naruke T, Tsuchiya R, Kondo H, Asamura H, Nakayama H. Implication of staging in lung cancer. Chest. 1997;112(4 Suppl):242S-8S.

18. Mountain CF. Revisions in the international system for staging lung cancer. Chest. 1997;111:1710-7.

19. PORT Meta-analysis Trialists Group. Postoperative radiotherapy in non-small-cell lung cancer: systematic review and meta-analysis of individual patient data from nine randomised controlled trials. Lancet. 1998;352:257-63.

20. Pass HI, Pogrebniak HW, Steinberg SM, Mulshine J, Minna J. Randomized trial of neoadjuvant therapy for lung cancer: interim analysis. Ann Thorac Surg. 1992;53:992-8.

21. Rosell R, Codina JG, Camps C, Maestre J, Padille J, Canto A, et al. A randomized trial comparing preoperative chemotherapy plus surgery with surgery alone in patients with non-small-cell lung cancer. $N$ Engl J Med. 1994;330:153-8.

22. Rosell R, Gomez-Codina J, Camps C, Javier Sanchez J, Maestre J, Padilla J, et al. Preresectional chemotherapy in stage IIIA non-smallcell lung cancer: a 7-year assessment of a randomized controlled trial. Lung Cancer. 1999;26:7-14.

23. Roth JA, Fossella F, Komaki R, Ryan B, Putnam JB, Lee JS, et al. A randomized trial comparing perioperative chemotherapy and surgery with surgery alone in resectable stage IIIA non-small-cell lung cancer. J Natl Cancer Inst. 1994;86:673-80.

24. Roth JA, Atkinson EN, Fossella F, Komaki R, Ryan MB, Lee LS, et al. Long-term follow-up of patients enrolled in a randomized trial comparing perioperative chemotherapy and surgery with surgery alone in resectable stage IIIA non-small cell lung cancer. Lung Cancer. 1998;21:1-6.

25. Pectasides D, Aspropotamitis A, Halikia A, Visvikis A, Antoniou F, Kalantaridou A, et al. Combination chemotherapy with carboplatin, docetaxel, and gemcitabine in advanced non-small-cell lung cancer: a phase II study. J Clin Oncol. 1999;17:3816-21.

26. Sandler AB, Nemunaitis J, Denham C, Pawel J, Cormier Y, Gatzemeier U, et al. Phase III trial of gemcitabine plus cisplatin versus cisplatin alone in patients with locally advanced of metastatic nonsmall-cell lung cancer. J Clin Oncol. 2000;18:122-30.

27. Comella P, Frasci G, Panza N, Manzione L, Cataldis G, Cioffi R, et al. Randomized trial comparing cisplatin, gemcitabine, and vinorelbine 
with either cisplatin and gemcitabine or cisplatin and vinorelbine in advanced non-small-cell lung cancer: interim analysis of a phase III trial of the southern Italy cooperative oncology group. J Clin Oncol. 2000; $18: 1451-7$

28. Krajnik G, Staudner AM, Thaler J, Greil R, Schmeikal S, Marhold F, et al. Vinorelbine-gemcitabine in advanced non-small-cell lung cancer (NSCLC) an AASLC phase II trial. Ann Oncol. 2000;11:993-8.

29. Kelly K, Crowley J, Bunn PA, Presant CA, Grevstad PK, Moinpour $\mathrm{CM}$, et al. Randomized phase III trial of paclitaxel plus carboplatin versus vinorelbine plus cisplatin in the treatment of patients with advanced non-small-cell lung cancer: a Southwest Oncology Group trial. J Clin Oncol. 2001;19:3210-8.

\section{Appendix}

The study was carried out as a trial by the Lung Cancer Surgical Study Group of the Japan Clinical Oncology Group, chairperson Professor Harubumi Kato, Tokyo Medical University.
The cases in this study were collected from the National Cancer Center Hospital East (Kanji Nagai); National Cancer Center Hospital (Ryosuke Tsuchiya); National Kinki Chuo Hospital (Takashi Mori); Osaka City General Hospital (Hiroto Tada); National Kyushu Cancer Center (Yukito Ichinose); Niigata Cancer Center Hospital (Teruaki Koike); Toho University School of Medicine (Keigo Takagi); Yokohama Municipal Citizen's Hospital (Masahiro Kase); Institute of Aging, Development, and Cancer, Tohoku University (Takashi Kondo); Kanagawa Cancer Center Hospital (Haruhiko Nakayama); Tochigi Cancer Center (Kohei Yokoi); Osaka Prefectural Habikino Hospital (Tsutomu Yasumitsu); Yamagata Prefectural Central Hospital (Toru Sato); National Defense Medical College (Yuichi Ozeki); Toyama Prefectural Central Hospital (Hideki Miyazawa); National Toneyama Hospital (Osamu Kuwabara); National Kure Hospital (Kenji Nakamura); and Shikoku Cancer Center Hospital (Hideyuki Saeki).

\section{IN THE MOVE?}

Don't miss a single issue of the journal! To ensure prompt service when you change your address, please photocopy and complete the form below.

Please send your change of address notification at least six weeks before your move to ensure continued service. We regret we cannot guarantee replacement of issues missed due to late notification.

\section{JOURNAL TITLE:}

Fill in the title of the journal here.

\section{OLD ADDRESS:}

Affix the address label from a recent issue of the journal here.

\section{NEW ADDRESS:}

Clearly print your new address here.

Name

Address

City/State/ZIP

\section{COPY AND MAIL THIS FORM TO:}

Mosby

Subscription Customer Service

6277 Sea Harbor Dr

Orlando, FL 32887
OR FAX TO:

407-363-9661

N/ Mosby
OR PHONE:

800-654-2452

Outside the U.S., call

407-345-4000 